\title{
JUBILEO EN LA NOVENA REGIÓN
}

Pablo Andrés Arnaudon

Muchos han hablado del jubileo hasta ahora. Las opiniones son complementarias y permiten vivir el jubileo, vibrar con él, interpretar y ponerse en camino en pleno conocimiento y conciencia.

Por mi parte, mi llegada reciente a la novena región me hace hablar en términos de deseo de vivir y compartir en estos parajes Ilenos de vivencia, historia, cultura y naturaleza.

Me propongo, después de una relectura biblica, opinar sobre los caminos posibles para vivir plenamente el espíritu del jubileo en el corazón del pueblo de nuestra región.

\section{A. Fuente Bíblica}

\section{El Jubileo en el pueblo de Israel:}

El pueblo de Israel, consecuente con la alianza hecha con su pueblo, Acoge el proyecto de Dios. Quiere superar la desigualdad acumulada a lo largo del tiempo y fomentar con equidad y dignidad una posibilidad de vida para todos. Dios pide implementar su plan a los reyes de Israel. Este plan de Dios abarca la relación con él, la relación con la naturaleza, la relación con las personas.

El pueblo de Israel tiene una preocupación ecológica innata y como no tiene los medios de abono y regeneración de las tierras, que tenemos ahora, decide poner los terrenos en barbecho cada 7 años ( $\operatorname{Lv} 25,2-4)$.

En un pueblo que está haciendo un proceso de sedentarización; en varias generaciones se crean desigualdades. Unos tienen suerte con la producción de sus campos, con el tiempo, con la cosecha, y otros no tienen buena suerte o han faltado de más trabajo y pierden sus tierras, las tienen que vender y ponerse ellos mismos al servicio de otros como obreros o, peor aun, como esclavos. De la misma manera que se van saneando los suelos, el pueblo quiere recuperar unas relaciones humanas en igualdad dentro del pueblo Lv 25, 8-14).

Esto pide un cambio de actitud en las personas, hacia la cordura y el perdón. Tienen que acordarse siempre que ellos también salieron de la esclavitud en Egipto y que tienen que mirar con ternura a los oprimidos, y guardar en el pueblo la igualdad entre las personas (Dt 15,7-15). El rey en Israel es el primer responsable en la práctica de la justicia en todo el Reino (Sal 72).

Después de sanear actitudes en la relación social, Dios por la voz de sus profetas quiere enderezar las actitudes de las personas en la oración y en la liturgia. Dios aborrece a los que fingen cuando están en la acción litúrgica y ofrecen sacrificios y después oprimen a sus hermanos (Is 58,1-9) 
Para Isaias la exigencia de justicia no es un camino optativo o por tincada, es el único camino para encontrar a Dios. Los signos de penitencia que presenta son también los que preparan al Reino futuro. Podemos decir lo mismo del año jubilar de los judios son los que preparan al Reino. El jubileo de los judíos es una imagen del Reino. La acción de justicia, recuerda y renueva la alianza de Dios con su pueblo y su gran misericordia. Para entrar en la alianza hay que rectificar su relación humana, devolver bienes, hacer justicia, y dar vida a los que perdieron bien por su culpa, o descuido.

Estos textos bíblicos quedan al nivel del deseo, porque no se ve su realización en Israel en los tiempos que siguen. Los profetas siguen recordando a los reyes y al pueblo la necesidad de hacer justicia. La intuición de Isaias sigue vigente: la vida es anterior a los sacrificios. La vida es el lugar verdadero del sacrificio agradable a Dios.

\section{Jesús acoge los signos del jubileo como signos del Reino de Dios}

Jesús cita Isaías 61 en su primer discurso público en la sinagoga. Agrega que anuncia un año de gracia del Señor que es el mismo del jubileo del pueblo de Israel en el levítico. Jesús anuncia su vida pública como un jubileo (año de Gracia del Señor). Agrega que esto se cumple Hoy.

Al abrir el año de gracia, Jesús proclama el Reino cercano. Los signos del año de gracia Del Señor son los signos del Reino de Dios (Lc 4,18). En estos signos del Reino de Dios encabezado por Jesús Cristo, hay dos tendencias complementarias: La primera es la justicia y la liberación de los pobres de toda opresión. Esta tendencia está manifestada en Lc 4,18 e Isaías, pero también en los que anuncian la venida de Jesús como Zacarías y María en su Magnificat.

La segunda tendencia es la vida y la abundancia de gracia de Dios, gracia como plenitud humana (Lc 6,38). Este reino anunciado es para dar vida, tener posibilidad de salvación para todos. Jesús que propone abrir un año de jubileo (año de gracia) a la vez anuncia el Reino en un mismo acto.

Jesús dice a los enviados de Juan el Bautista en Mt 11,4-5 que estos signos se están realizando ahora, como dice en Lucas Hoy se declara el año de gracia del Señor. Este hoy es el tiempo de Jesús es el tiempo de la realización del misterio de Dios en el mundo, el Hoy de Dios. Es el signo de lo que va a pasar en el Reino. Jesús comunica estos signos hoy y será la cabeza del Reino mañana; él es la fuente de vida, y de amor en el Reino.

El mundo sigue siendo desigual e injusto, tanto en el tiempo de Jesús como en el tiempo posterior. Los signos de Jesús son como el trigo que crece en medio de la cizaña; el Reino es desde ahora cercano: presente y escondido. Jesús no termina de repetir con sus apóstoles «El Reino está cerca». El hoy de Jesús no es una totalidad de justicia en el mundo, es más bien una muestra del Reino futuro. De la misma manera los cristianos viven esta muestra de vivencia de justicia como semilla del Reino en el mundo, manifestando así este Reino está cerca, está entre nosotros. 


\section{B. Jubileo 2000}

El papa declaró un año de jubileo para este año 2000 Aunque no sea exactamente una correspondencia con los 2000 años del nacimiento de Jesús, a causa de las imprecisiones del calendario cristiano, pero adaptándonos a éste entramos en la tradición de los jubileos de Israel cada 50 años. El año 2000, múltiple de 50 , puede entrar en la tradición de los jubileos. El papa podría elegir además cualquier año para que lo sea. El ha preferido este como entrada del nuevo milenio.

"Todos tenemos en nosotros el ansia de llamar a la paz y a la reconciliación. En el año 2000 la Iglesia ofrece a la gente de nuestro tiempo el amor de Dios que restablece en la persona de su hijo la presencia solidaria de Dios con el ser humano," dice el papa en su envío para el jubileo.

Estas palabras del papa que anuncia el año del jubileo pretenden dar un cauce real y concreto a la línea del anuncio de los profetas y de Jesús. Jesús ha abierto el tiempo del Reino. La fuerza de la presencia cristiana en el mundo es semilla del Reino; está acá, entre nosotros y levanta como la levadura, aunque uno no lo vea si no presta atención. Porque estamos en un cambio de siglo el papa quiere memorar claramente el tiempo de salvación, de encarnación de Jesús y de acogida del Reino de Dios presente en el mundo. Quiere manifestar la muestra de los Signos del Reino en nuestro mundo de hoy.

Veo las dos líneas complementarias del evangelio en la intención del papa. Primero el año jubilar quiere recuperar el sentido de justicia en realizaciones múltiples insertas en el mundo, en el medio de él que rectifiquen situaciones de injusticias. Segundo, en signos de presencia y abundancia de la gracia, de la bondad, del perdón, de la reconciliación, de la misericordia, como es la medida rebosante de vida en Lc 6,38.

Quiere decir que cada cristiano ha entendido el sentido vivo del año jubilar y quiere estar presente en el mundo, "donde las papas queman", dando testimonio de la misericordia, de la justicia, del don de Dios a los hombres, viviendo más intensamente en este año, lo que se propone vivir como una misión de toda la vida. EI Jubileo quiere intensificar en un año especial la misión cristiana que es de todos los tiempos.

Las personas lejanas a la Iglesia y al misterio de la salvación tendrian que descubrir algo del aporte de vida que quieren dar los cristianos comprometidos con el año jubilar desde el rincón en el cual viven. En esta forma, pasaremos del nivel del deseo a un nivel de realización real, posible, alcanzable a nuestro nivel y a la vez significativas del Reino que surge entre nosotros.

El año jubilar intensifica lo que queremos hacer siempre en nuestra misión cristiana en el mundo. Este año puede vivificar el camino emprendido en nuestra misión cristiana y despertar nuevas personas hacia la misión.

En este sentido el llamado del papá es osado. El papa se atreve a dar confianza a los cristianos para que realicen de manera concreta la justicia y misericordia en su ámbito de vida. Será posible o será presunción. Si bien en tiempos difíciles la Iglesia ha sabido testimoniar y ser voz de los sin voz, ella no ha elegido este camino, sino que los acontecimientos exteriores la ha forzado a reaccionar. Esta vez el papá 
quiere que la Iglesia sea signo del Reino en el mundo por una voluntad interior. Es mucho confiar en los cristianos; pero Jesús confió en Zaqueo en quién nadie hubiera confiado. Es decirles: "salgan de su rutina y actitud remolona para vivir una aventura, miren el mundo en el cual viven, enamórense de sus vivencias y acontecimientos diarios, háganse arte y parte". La Iglesia se atreve a decir al mundo: "miren, queremos mostrarles signos de justicia, de misericordia y abundancia de vida y de atención especial a los pobres; queremos decirles que el Reino de Dios vale la pena". ¿Nos damos cuenta en qué lindo plan nos ponemos?.

\section{Tenemos algunos temores y muchos anhelos}

La celebración del jubileo pudiera reducirse a actos externos que no lograrían llegar a las raíces de la vida y de la intención del papa.

La celebración puede abarcar el interior de la iglesia sin lograr la amplitud del llamado del mundo. O ser solamente invitaciones a la gente de "afuera" en actos de la Iglesia, lo que es valioso pero pasa al lado de todo el sentido de inserción en la vida y en el mundo, y además queda limitado a simpatizantes cercanos a nosotros.

No lograríamos hacer oír esta voz a todos los rincones, compartir nuestra alegría. Quedaríamos frustrados porque no habríamos sabido interpretar el espíritu del jubileo y el pedido del papa. No habría ningún significado para las personas del mundo, no habría ninguna muestra de los signos adyacentes del Reino de Dios para todo el mundo de afuera.

Quisiéramos que esta iniciativa del papa en el final de su vida y en el principio del milenio sea significativa para el mundo. Que los signos del Reino se hagan presentes por intermediario de los cristianos y que el mundo tenga una luz, una aurora, un significado en su historia. Que los que están lejos puedan reconocer algo de lo que quisimos lanzar; qué a través de nuestro humilde actuar el mundo pueda reconocer algo de los signos del Reino, que la comunidad de los creyentes se comprometa a vivir en el mundo sabiendo que ha de ser fermento y alma de la sociedad humana, que debe ser renovada en Cristo y transformada en familia de Dios.

\section{2. ¿Qué supone en la lógica religiosa y humana este pedido del papa?}

\section{a) Una relación entre culto y vida:}

Bendigo la sensibilidad de la gente y sus distintas formas de llegada a lo religioso, también miro con cariño a los que organizan el culto y este aspecto del año santo. La parte cultual está considerada y cubierta para este jubileo del año 2000 , no será aquí mi propósito.

No niego tampoco que la Iglesia convoque a gentes en su seno para invitarle a que venga y mire, y que comparta algo de fiesta o de lectura del mensaje. El año jubilar será lleno de propuestas de invitaciones internas a la asambleas eclesiales. Desde adentro invitamos a los de afuera para venir adentro y conozcan algo de nuestra reflexión y festejo a partir de los que hemos vivido en el corazón del mundo. 
Lo que me parece importante subrayar y decir con fuerza es que el culto no puede ser el único motor de este año jubilar. Se necesita una relación profunda, integrada entre lo que pasa en la vida y lo que se festeja en el culto. En la línea de lo que Jesús dice en Mt 5,24-25: si traes tu ofrenda al altar y alli te acuerdas de que tu hermano tiene algo contra ti, 24 deja alli tu ofrenda al altar y anda para reconciliarte primero con tu hermano, $y$ entonces ven y presenta tu ofrenda.

Acostumbramos a más expresión litúrgica que expresión de vida. Desearía que el jubileo fuera la ocasión de invertir la máquina y que implementáramos más vida en el mundo que expresión intraeclesial. Me interesa el otro camino, la presencia de los cristianos en todos los ámbitos de la vida del mundo, trabajo, municipalidad, fiestas y diversión humana, política... Aqui veo la posibilidad de realizar estas semillas de Reino, estas actuaciones de justicia, solidaridad y gracia de Dios, bondad, misericordia, perdón... Como Jesús se ha encarnado en el mundo, entre nosotros, nos invita también a nosotros a insertarnos en el mundo arrimados a sus realidades, sin corrernos.

La vida es primera y se festeja en la liturgia del jubileo. La liturgia a su vez puede llevar a la conversión significativa y efectiva en la vida. Lo que importa es que en la vida encontremos la expresión de justicia y la misericordia, gracia y perdón del Señor. Que lo encontremos en todos los niveles personales, grupales, comunales, nacionales y mundiales, en todos los ámbitos de relación humana de la vivienda del trabajo de lo social de lo político. Esto permitirá que en el culto se pueda contar, festejar y gozar lo vivido en el mundo.

Un culto sin vida se vuelve rutina, o hipocresía como lo manifiesta Isaías en el capítulo 58. Un culto en conexión con la vida experimenta la relación con el Señor en toda su dimensión y redescubre el sentido de la fiesta.

\section{b) Gestos proféticos:}

Los profetas muestran gestos para manifestar la actuación de Dios, después explican porque han hecho estos gestos. Jesús hace lo mismo en muchas ocasiones hace un gesto que atrae la atención y después contesta a los interlocutores que piden explicaciones. A partir del gesto Jesús introduce su palabra, su mensaje. Por ejemplo cuando le traen la mujer adúltera en Jn 8 el escribe en la arena, después explica, a los que quieren condenar y a la mujer ,muestra su actitud de misericordia, con una posibilidad de vida nueva. Él Sana al paralítico y proclama que puede perdonar los pecados...

Los gestos de Jesús entran en la cultura de su pueblo, cultura campesina, cultura de pastores de ovejas, cultura de medicina natural. Es posible que a veces nos falta estar en el ambiente cultural mismo para entender algunos de esos gestos de Jesús, como cuando con su saliva y con tierra hace barro para untar los párpados del ciego. Jesús hace gestos en el corazón mismo de su anuncio en sus partes más importantes; lavando los pies, interpela a los discípulos, rompe barreras sociales del momento; luego introduce su mensaje mostrando su vocación de Servidor De Dios e invita a ser servidores de los hermanos. En el episodio del Templo (Jn 2,13-16), hizo un látigo de cuerdas para echar los vendedores de animales en el templo.

La gente entiende las acciones que les tocan en su vida propia. Cuando Mons 
Larrain entregó los fundos de la Iglesia a los inquilinos para que se hicieran dueños, fue un gesto significativo que llamó la atención en todo Chile además de tocar a fondo a los interesados. El año jubilar pide actos significativos que hablan a la gente sencilla donde esté en su propio ambiente, les llame la atención, demostrando una misericordia que llega. Estos gestos pueden venir desde cualquier parte donde hay cristianos insertos en nuestra región.

El jubileo puede ser marcado por un montón de gestos chicos que demuestran la ola de misericordia presente y porque no también gestos grandes que pueden calzar con la vida contingente del chile de hoy.

Podemos actuar en hechos diarios chicos que tengan sentido y que sean muy significativos para nosotros mismos y para nuestro entorno, Hay signos grandes y signos diarios, familiares que también tienen su significado y son profecía, anuncio para los demás e interpelan.

Pero hacemos miles de hechos todos los días de nuestra vida y es muy posible que si algunos quieren ser conscientemente proféticos, nos encontremos en contradicción con otros hechos de nuestra vida que son más bien negativos y escandalizan. Cuantas personas hacen atenciones a los pobres y tiene actitudes diarias de desprecio hacia ellos o claras injusticias. Las expresiones populares expresan estas contradicciones. Nuestros gestos generosos se contradicen con nuestro egoísmo diario. La queja de la gente viene de multitudes de actitudes intransigentes. Yo tengo razón y por tener razón, ser intransigente con las personas; así se engendran situaciones de catástrofes familiares y sociales. Los campos de estas intransigencias son múltiples.

Son tan inconscientes nuestras inconsecuencias que vivimos la liturgia en plena tranquilidad sin pensar que alguien puede tener algo en contra de nuestras actuaciones. Hacer gestos significativos de justicia y bondad para el anuncio del Reino supone conjuntamente rectificar nuestras contradicciones y signos negativos, contradictorios al Reino. Este trabajo en nosotros ya es muy misionero. Puebla decía a los Jóvenes: "evangelizándose evangelicen."

El jubileo nos llama a la inserción y no a la condescendencia, a la vida en solidaridad más que a la caridad...

\section{El jubileo en la IX $\mathbf{X}^{\circ}$ Región}

¿Qué significa hoy la justicia del Reino, el perdón en relación con la perdida de las tierras, el compartir del pan, la ruptura de esclavitudes? ¿Qué significa hoy y en la IXa región? Que los profesionales de toda clase, los operarios, los obreros, los campesinos, las mujeres insertas en poblaciones, los estudiantes en su sala de clase y en su universidad, les presos los enfermos, nos digan qué podemos hacer, vivir, cambiar. ¿Cómo pueden encontrar formas de liberación ahora?

La Iglesia ha descubierto desde EL Vaticano II la importancia de la penetración de la cultura en la evangelización, es desde adentro de las culturas que se puede dialogar con el mensaje evangélico y convertirse. Encontrar en la cultura la manera de encontrar a Dios, encontrar en el evangelio la manera de hacer evolucionar a la cultura. 
Lo mismo se puede decir ahora del jubileo en la cultura mapuche, tan propia de nuestra región, pero también la cultura campesina, la cultura obrera, operaria, patronal. Cada cual tiene que encontrar en sus formas de vivir la manera de comulgar a la justicia y a la misericordia de Dios que viene y descubrir los signos del Reino que se pueden hablar al mundo en el cual está inmersos. A veces es intensificar un trabajo pastoral que ya está encaminado.

Se propone anudar lazos con el pueblo mapuche que desconfía de la política de los wincas después de una larga historia de aprovechamientos, mentiras, obligación de silencio; conocer la historia de la tierra y de todas las tierras de América latina que además de ser sagrada ha sido sujeta a tantos conflictos martirios y muertes. Aprovechar el jubileo para mostrar una relación de bondad y de olvidar intransigencias ojalá de los dos lados. Que los mapuches puedan sentir con este año un momento de sensibilidad de los cristianos del mundo winca hacia ellos sensibilidad que hace entrar en la problemática conocer de adentro, vibrar con sus anhelos y sufrimientos. Anhelo que los cristianos mapuches como los cristianos de todas las culturas nativas en América latina encuentren caminos originales para hacerse entender. Aquí especialmente esta nueva relación supone revisar muchas actitudes de desprecio, suficiencia, impaciencia, que ni sospechamos en nuestras actitudes diarias.

Ojalá los que han sufrido el robo de sus tierras, la opresión y la muerte, la desaparición y la ausencia de justicia encuentren sensibilidad en gente que se dice cristiana en el Chile de Hoy. El camino de la reconciliación en la región como en Chile no puede ser lo que oímos tanto en las radios: olvidar, pasar la esponja, pedir a las víctimas perdonar a los victimarios sin que estos reconozcan sus culpas; bajo palabras de reconciliación, esto encubre nuevas injusticias. Para vivir el perdón y la reconciliación, se necesita rectificar claramente las injusticias.

\section{SUGERENCIAS}

\section{En el camino de recuperación de igualdad y justicia}

Los cristianos insertos en el mundo se sienten muchas veces encerrados en sistemas que les imponen relaciones humanas intransigentes. Saben que es iluso querer suprimir de un golpe mágico las diferencias en una civilización marcada por la economía y la competencia, uno puede hacerse "dócil a la acción del Espíritu», como lo dice el papa para encontrar caminos que allanen diferencias y avance hacia un mayor respeto de las personas.

Revitalizar la cercanía al mundo de los pobres, de la marginación que llamamos ahora excluidos, en medio de nuestros trabajos o poblaciones en acciones solidarias que contesten a situaciones urgentes.

Buscar caminos de acompañamiento de los que viven en la enfermedad, el dolor o la cercanía de enfermos en su familia, viviendo con ellos la compasión pero también un camino hacia la esperanza..

Vivir un año positivo en un camino de vida y resurrección, que levanta el ánimo de los heridos de la sociedad, acompaña, vitaliza. De hecho nadie se pondría en 
este plan de acción sin tener en él la firme convicción que el Señor nos da la vida y una vida que vale la pena.

Que los religiosos, religiosas, sacerdotes sepan escuchar la voz de los laicos en su búsqueda de camino cristiano en su propio campo, que preparen su corazón para dejarse enseñar por los cristianos lúcidos e interpelar en las actitudes contradictorias con la misericordia, la vida de los pobres o la justicia. Los religiosos no son los que dan la pauta en la búsqueda de la justicia y la misericordia en el mundo, tienen que dejar a los laicos en su propia tarea, para no disminuir su creatividad ni achicar su visión propia.

Que los sacerdotes se hagan acompañantes de laicos insertos en el mundo, sin siempre pedirles tareas parroquiales. Que sepan acompañarles en la tarea de misión, reconociéndola, vivificándola, analizando y festejándola.

\section{Nuestro vida eclesial, nos propone acoger la indulgencia de Dios}

Después del acto fundamental del cristiano vivido en la inserción es bueno festejar con los hermanos como los hicieron los discípulos mandados de dos por Jesús, en Lc 10. El hecho de haber vivido la fuerza de los signos del Reino en el mundo nos da otro carácter a la vivencia litúrgica. Así y solamente así podemos dar también sugerencias para las liturgias que podemos vivir más adelante.

Podemos hacer de nuestras liturgias no una lectura de rúbricas sino un gran festejo de acontecimientos vividos en justicia y misericordia. Se sugiere descubrir a fondo la intención divina de misericordia, profundizar, releer compartir los textos evangélicos, vitalizar la indulgencia de Dios a través de sus actos sacramentales, como penitencia y eucaristía. La mirada hacia los pobres en la liturgia nos cambia el corazón y nos hace entrar en el movimiento de la misericordia de Dios en todas sus dimensiones.

Introducir a la liturgia la alegría de toda liberación en actos de fiesta que le corresponda. Los hechos de la vida los testimonios de conversión son parte de esta fiesta litúrgica. Inventar en esta liturgia signos que hablen a la gente y signifiquen lo que pasa en la vida de esta transformación y vivencia de la misericordia.

La peregrinación en el pueblo de Israel tenía un sentido de unificación de todas las tribus como referencia al Dios único para todos. Se hacía con largas marchas hacia Jerusalén por las grandes fiestas. La peregrinación tiene un significado distinto pero real, cultural para la gente de nuestra región. Es una puesta en marcha con el otro, un empezar a caminar en nuestra vida, una puesta en movimiento de nuestras vidas sedentarias y arrinconadas, en comunión con personas lejanas a la fe que viven y buscan. Es una des-instalación; podemos introducir etapas de vida en la peregrinación como etapas de descubrimiento de la vida del mundo de su llamado, como un panorama que nos permitirá después vivir más la misericordia del Señor.

Los actos de Iglesia jerárquica pueden ser también una promesa para el futuro, una puesta en marcha de todo nuestro ser en comunión con el otro. El pedido de 
perdón del papa en el muro de las lamentaciones tiene significado mundial y puede aportar algo en la relaciones inter-religiosas. Lo que hace el papa al nivel de medio de comunicación, nosotros lo hacemos en la micro realización diaria.

Este lanzamiento nos invita a sobrepasar el tiempo del año 2000 y emprender un estilo de vida cristiana que camina en favor del Reino en toda nuestra vida.

Ojalá que la juventud que entra en el mundo de los adultos no encuentren solamente dureza, indiferencia y lucha por lo económico frío sino también actitudes humanas, de bondad y entendimiento de sus situaciones de vida.

Ojalá que la juventud universitaria que encontramos más de cerca en nuestras facultades encuentren en sus padres como en los profesores personas que les indiquen un camino de real servicio en su profesión y no de elitismo, alejamiento del pueblo, búsqueda de dinero, insensibilidad hacia los pobres. 